\title{
A pharmacokinetic study of Isatin in Beagles' bodies
}

\author{
AILING REN $^{1}$, BENHUA SU $^{1}$, SIYONG YE ${ }^{2}$, XIA WEI $^{2}$, ZHAOGUO FANG $^{1}$, QIAN WANG $^{1}$, \\ JIAN ZHANG ${ }^{1}$, WEN XU ${ }^{3}$, WANG YUE ${ }^{3}$, LEI YIN ${ }^{3}$, ZHANTAO LIU ${ }^{3},{\text { XIAOLING } \text { LI }^{3} \text { and BO DING }}^{1}$ \\ ${ }^{1}$ Shandong Provincial Hospital Affiliated to Shandong University, Jinan, Shandong 250021; ${ }^{2}$ The Second People's Hospital of \\ Jinan City, Jinan, Shandong 250001; ${ }^{3}$ The Affiliated Hospital of Qingdao University, Qingdao, Shandong 266003, P.R. China
}

Received November 19, 2015; Accepted April 6, 2016

DOI: $10.3892 /$ etm.2016.3232

\begin{abstract}
Isatin are marine active drugs that exert anti-cancer effects, have a cancer-prevention function, and possess many pharmacological activities. The study aimed to examine the pharmacokinetics of a single intravenous injection and oral medication of Isatin given to Beagles. Nine male and nine female Beagles were injected with $30 \mathrm{mg} / \mathrm{kg}$ of 2,3-indole quinones. The animals were divided into 3 groups $(n=6$ per group) and lavaged with a dose of 15,30 and $60 \mathrm{mg} / \mathrm{kg}$, respectively. Blood samples were collected prior to the medicine delivery $(0 \mathrm{~h})$ and $0.083,0.25,0.5,1,2,4,6,8$ and $24 \mathrm{~h}$ post-medicine delivery. The blood plasma samples were analyzed using the liquid chromatography-mass spectrometry (MS)/MS method following pretreatment for the protein precipitation. Pharmacokinetics software was applied to calculate relevant pharmacokinetic parameters through the atrioventricular model. The drug concentration in plasma decreased rapidly following the intravenous injection of Isatin. After $8 \mathrm{~h}$, the prototype drugs could not be tested in the plasma and only trace amounts of drugs were tested in one dog, which was considered to be an endogenous drug. Indole quinone was absorbed following lavage into Beagles and peaked in $<1 \mathrm{~h}$, and the drug concentration in the plasma decreased rapidly. After $8 \mathrm{~h}$, the prototype drugs could not be tested in the plasma. The elimination of the two drugs in the body had no evident gender differences. In conclusion, Isatin is rapidly absorbed in bodies of Beagles. Within the dose range of $15-60 \mathrm{mg} / \mathrm{kg}$, no linear relationship was observed for the increase in $\mathrm{Cmax}$ and $\mathrm{AUC}_{0-\mathrm{t}}$ values with the increased dose.
\end{abstract}

\section{Introduction}

Isatin is a type of marine active drug exerting anti-cancer effects, with a cancer-prevention function, and is an endogenous substance in human bodies, which possesses pharmacological

Correspondence to: Dr Bo Ding, Shandong Provincial Hospital Affiliated to Shandong University, 324 Jingwu Road, Jinan, Shandong 250021, P.R. China

E-mail: boding@yeah.net

Key words: 2,3-indole quinine, Beagles, pharmacokinetics, intravenous injection, oral medication activities (1-3), such as nerve protection, antibacterial and antivirus activities. Through the synthesis of a large number of materials, we aimed to identify a new drug and conducted relevant investigations $(4,5)$, funded by the National Major Projects for New Drugs Innovation.

To design an improved drug dose and administration regimen, based on earlier studies of the lavage and dose of rats, pharmacokinetic studies were conducted following oral and intravenous injection of Isatin given to Beagles.

\section{Materials and methods}

Drugs and reagents. Isatin was purchased from Shanghai Xin Sheng Yuan Biological Pharmaceutical Co., Ltd. (Shanghai, China) and served as a control. Internal standard, quetiapine, was purchased from Maddie Xipuya Medical Technology Co., Ltd. (Shanghai, China). Methanol of HPLC grade was purchased from Burdick and Jackson (Morristown, NJ, USA). Formic acid of HPLC grade and ultrapure water were purchased Acros Organics (Geel, Belgium).

Instruments and equipment. Liquid chromatography (LC) instrument (Agilent 1200) and mass spectrometer (6410B) were purchased from Agilent Technologies, Inc. (Santa Clara, CA, USA), and the electrospray ion source and tandem quadrupole mass analyzer were purchased from Zhejiang Haochuang Biotechnology Co. (Hangzhou, China). The data processing system was MassHunter software (Agilent Technologies, Inc.). The following instruments were also purchased: Vortex-Genie 2, a vortex generator (Scientific Industries, Inc., Bohemia, NY, USA); a small desktop high-speed refrigerated centrifuge (5417R; Eppendorf, Hamburg, Germany); a trace analytical balance [XP26; Mettler-Toledo Instrument (Shanghai) Co., Ltd., Shanghai, China]; and an ultrapure water machine (Millipore Corp., Billerica, MA, USA). The chromatographic column used was Venusil XBP PH, $5 \mu \mathrm{m}, 100 \times 2.0 \mathrm{~mm}$.

Experimental animals. Nine male and nine female Beagles, weighing 7.80-9.60 kg were purchased from Beijing Thomas Biotechnology Co. Ltd. (Beijing, China), license no.: SCXK (Beijing) 2010-0003.

\section{Experimental methods}

Solution preparation. A suitable amount of Isatin (10 g) was weighed and the required concentration was compounded 
Table I. The pharmacokinetic parameters after intravenous injection of Isatin to Beagles.

\begin{tabular}{lcccrrr}
\hline Animals & $\mathrm{AUC}_{0-\mathrm{t}}, \mu \mathrm{g} * \mathrm{~h} / \mathrm{l}$ & $\mathrm{AUC}_{0-\infty}, \mu \mathrm{g} * \mathrm{~h} / \mathrm{l}$ & $\mathrm{MRT}, \mathrm{h}$ & $\mathrm{T}_{1 / 2}, \mathrm{~h}$ & $\mathrm{CL}, \mathrm{l} / \mathrm{h} / \mathrm{kg}$ & $\mathrm{Vss}, \mathrm{l} / \mathrm{kg}$ \\
\hline Male & $2391 \pm 669$ & $2418 \pm 675$ & $1.05 \pm 0.26$ & $0.89 \pm 0.24$ & $6.57 \pm 1.98$ & $7.98 \pm 0.34$ \\
Female & $2260 \pm 446$ & $2293 \pm 438$ & $1.82 \pm 0.38$ & $1.13 \pm 0.47$ & $6.72 \pm 1.41$ & $11.49 \pm 7.19$ \\
Average & $2326 \pm 514$ & $2356 \pm 513$ & $1.44 \pm 0.98$ & $1.01 \pm 0.36$ & $6.64 \pm 1.54$ & $9.73 \pm 4.94$ \\
\hline
\end{tabular}

$\mathrm{AUC}_{0-\mathrm{t}}$, area under the perindopril concentration-time curve; $\mathrm{AUC}_{0-\infty}, \mathrm{AUC}$ zero to infinity; $\mathrm{CL}$, clearance; MRT, mean residence time.

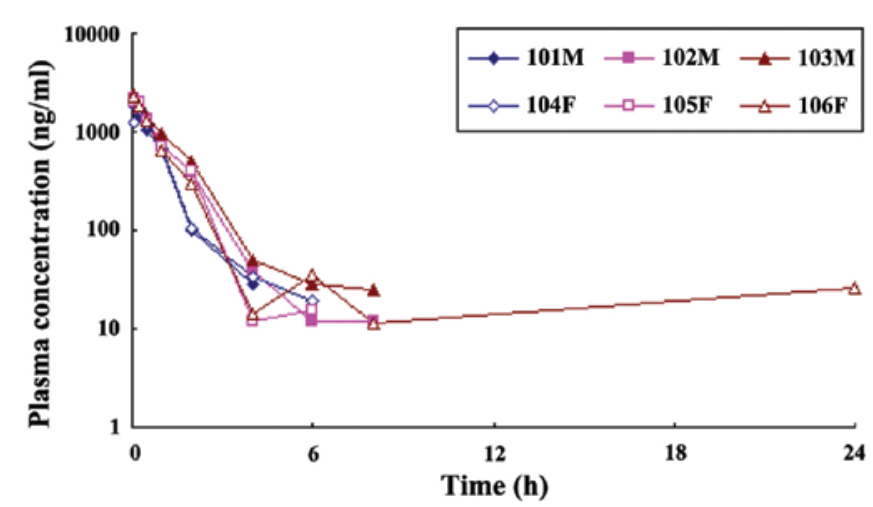

Figure 1. Blood Isatin concentration curve after injection of $15 \mathrm{mg} / \mathrm{kg}$ of drug was injected into Beagles' vein.

according to the dose and dose volume. West astragalus gum solution (1.25\%) was compounded for the gavage, as well as $5 \%$ DMSO and $40 \%$ polyethylene glycol (both from Haian Petrochemical Co., Nantong, China), and 55\% physiological saline (Shanghai Chemical Reagent Co., Shanghai, China) was compounded for intravenous injections.

Drug delivery and sample collection. Intravenous drug delivery was carried out in the Beagles. Briefly, 3 male and 3 female healthy beagles were injected with $15 \mathrm{mg} / \mathrm{kg}$ of Isatin through the saphenous vein at a dosing volume of $1.5 \mathrm{ml} / \mathrm{kg}$. Blood $(1 \mathrm{ml})$ was taken from the jugular vein prior to adminstration of test substances $(0 \mathrm{~h})$ and after $0.083,0.25,0.5,1,2$, 4, 6, 8 and $24 \mathrm{~h}$, in the K2EDTA tube and kept on ice. Blood samples were centrifuged at $1,900 \mathrm{x}$ g for $10 \mathrm{~min}$ at $4^{\circ} \mathrm{C}$. Plasma was collected and stored at $-80^{\circ} \mathrm{C}$ until analysis.

Intragastric adminstration of Beagles was subsequently carried out. Briefly, 3 male and 3 female dogs in each dose group, were fasted for 14-18 h, albeit drinking water was provided ad libitum prior to drug delivery. The animals were lavaged with Isatin at doses of 15, 30 and $60 \mathrm{mg} / \mathrm{kg}$, respectively at a dosing volume of $2 \mathrm{ml} / \mathrm{kg}$. Blood $(1 \mathrm{ml})$ was taken from the jugular vein prior to adminstration of test substances $(0 \mathrm{~h})$ and after $0.083,0.25,0.5,1,2,4,6,8$ and $24 \mathrm{~h}$ in the K2EDTA tube and kept on ice Blood samples were centrifuged at $1,900 \mathrm{x} \mathrm{g}$ for $10 \mathrm{~min}$ at $4^{\circ} \mathrm{C}$, and plasma was separated and stored at $-80^{\circ} \mathrm{C}$ prior to analysis.

Measurement methods of plasma samples. The LC-mass spectrometry (MS)/MS method was used to measure the concentration of Isatin in the plasma at different time points
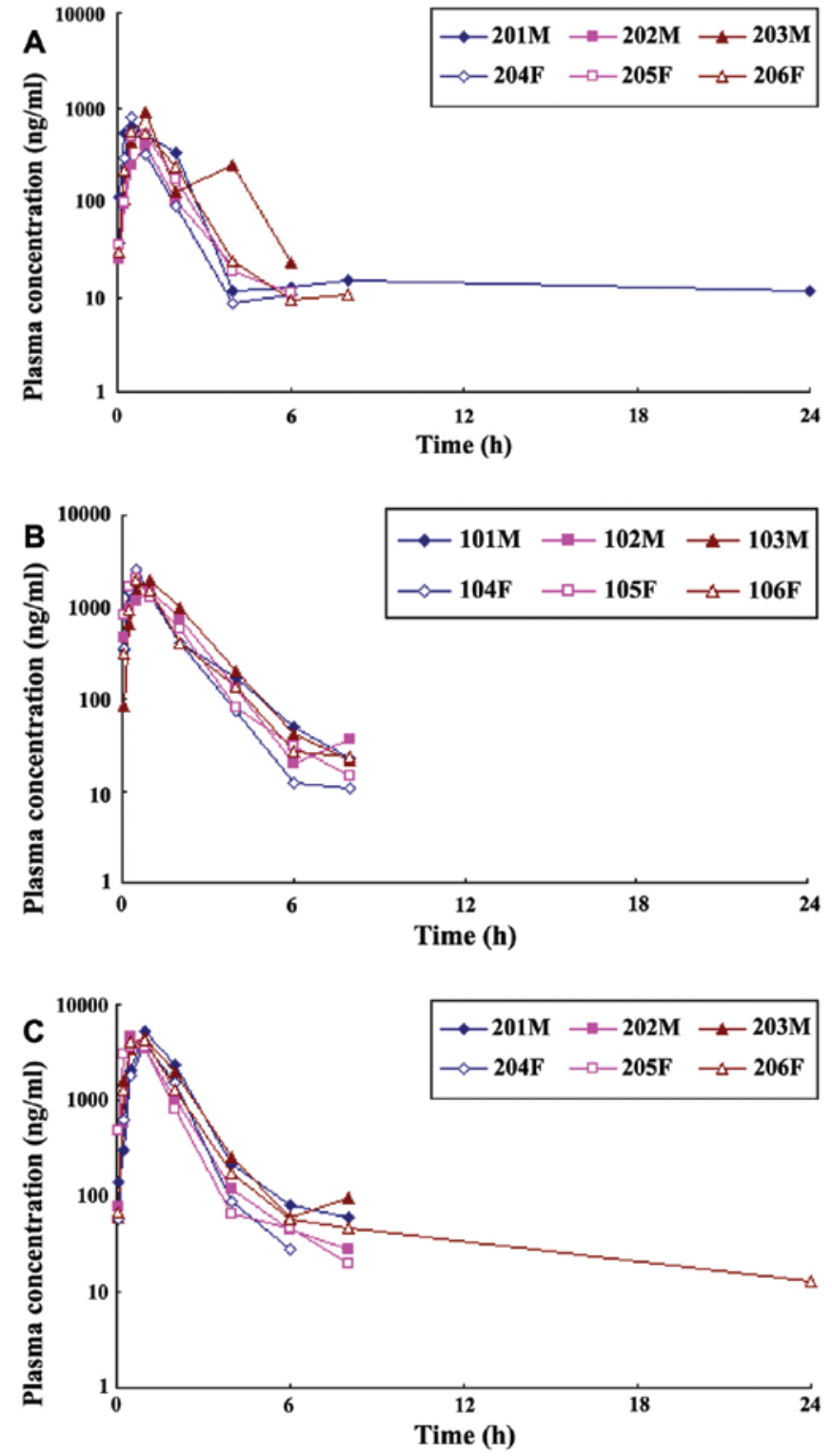

Figure 2. Blood concentration-time curve after Isatin was gavaged into Beagles at a dose of (A) 15, (B) 30 and (C) $60 \mathrm{mg} / \mathrm{kg}$.

after drug injection. The required conditions for the measurement of Isatin in the plasma were similar to those reported in rats earlier (6), and were used in blank dog plasma to validate the methodology. The specificity, sensitivity, linearity, rate of extraction recovery, precision in the day or between days, stability, and the matrix effect of the analytical method was 
Table II. The pharmacokinetic parameters after different dosages of Isatin are lavaged into Beagles.

\begin{tabular}{|c|c|c|c|c|}
\hline \multirow[b]{2}{*}{ Pharmacokinetic parameters } & \multirow[b]{2}{*}{ Animals } & \multicolumn{3}{|c|}{ Beagles' drug dosage of lavage (mg/kg) } \\
\hline & & 15 & 30 & 60 \\
\hline \multirow[t]{3}{*}{$\mathrm{T}_{\max }, \mathrm{h}$} & Male & $0.67 \pm 0.29$ & $0.83 \pm 0.29$ & $0.83 \pm 0.29$ \\
\hline & Female & $0.67 \pm 0.29$ & $0.50 \pm 0.00$ & $1.00 \pm 0.00$ \\
\hline & Average & $0.67 \pm 0.26$ & $0.67 \pm 0.26$ & $0.92 \pm 0.20$ \\
\hline \multirow[t]{3}{*}{$\mathrm{C}_{\max }, \mu \mathrm{g} / 1$} & Male & $634 \pm 253$ & $1,902 \pm 357$ & $4,812 \pm 412$ \\
\hline & Female & $619 \pm 152$ & $2,213 \pm 347$ & $3,891 \pm 284$ \\
\hline & Average & $631 \pm 187$ & $2,057 \pm 358$ & $4,352 \pm 596$ \\
\hline \multirow[t]{3}{*}{$\mathrm{AUC}_{0-\mathrm{t}}, \mu \mathrm{g} * \mathrm{~h} / \mathrm{l}$} & Male & $1,012 \pm 466$ & $3,578 \pm 553$ & $8,071 \pm 1464$ \\
\hline & Female & $922 \pm 161$ & $3,184 \pm 128$ & $6,748 \pm 927$ \\
\hline & Average & $967 \pm 316$ & $3,381 \pm 419$ & $7,409 \pm 1313$ \\
\hline \multirow[t]{3}{*}{$\mathrm{AUC}_{0-\infty}, \mu \mathrm{g} * \mathrm{~h} / 1$} & Male & $1,031 \pm 459$ & $3,624 \pm 541$ & $8,164 \pm 1509$ \\
\hline & Female & $937 \pm 163$ & $3,212 \pm 128$ & $6,793 \pm 923$ \\
\hline & Average & $984 \pm 313$ & $3,418 \pm 418$ & $7,479 \pm 1348$ \\
\hline \multirow[t]{3}{*}{$\mathrm{T}_{1 / 2}, \mathrm{~h}$} & Male & $0.71 \pm 0.10$ & $1.19 \pm 0.19$ & $1.04 \pm 0.09$ \\
\hline & Female & $0.95 \pm 0.15$ & $1.20 \pm 0.36$ & $1.70 \pm 0.89$ \\
\hline & Average & $0.83 \pm 0.18$ & $1.19 \pm 0.26$ & $1.37 \pm 0.67$ \\
\hline \multirow[t]{3}{*}{ MRT, h } & Male & $2.06 \pm 1.23$ & $1.69 \pm 0.07$ & $1.58 \pm 0.2$ \\
\hline & Female & $1.40 \pm 0.23$ & $1.37 \pm 0.17$ & $1.61 \pm 0.47$ \\
\hline & Average & $1.73 \pm 0.87$ & $1.53 \pm 0.21$ & $1.60 \pm 0.32$ \\
\hline
\end{tabular}

$\mathrm{AUC}_{0-\mathrm{t}}$, area under the perindopril concentration-time curve; $\mathrm{AUC}_{0-\infty}, \mathrm{AUC}$ zero to infinity; MRT, mean residence time.

confirmed to the relevant provisions of the biological sample analysis worldwide (7-9).

Data analysis. The pharmacokinetic parameters of Isatin were analyzed and processed by the atrioventricular model of WinNonlin5.2 software (Pharsight Corporation, Mountain View, CA, USA). The experimental data were presented as mean \pm standard deviation).

\section{Results}

Blood concentration as well as concentration and time curve. After $15 \mathrm{mg} / \mathrm{kg}$ Isatin $(\mathrm{n}=6)$ was injected into the Beagles' vein, the association between blood concentration of Isatin and time were measured (Fig. 1). The drug concentration in the plasma decreased rapidly after the intravenous injection of Isatin. After $8 \mathrm{~h}$, the prototype drugs could not be tested in the plasma and only trace amounts of drugs were tested in one dog, which was considered an endogenous drug. Elimination of the drug in the body had no obvious gender difference. WinNonlin pharmacokinetic software was used to process the plasma concentration of Isatin using an atrioventricular model following drug administration in dogs and the pharmacokinetic parameters after fitting (Fig. 1).

The curve of blood Isatin concentration and time are shown in Fig. 2 after three different doses of Isatin were respectively lavaged into the Beagles. The blood Isatin concentration peaked within $1 \mathrm{~h}$, and then decreased rapidly. After $8 \mathrm{~h}$, the prototype drugs could not be tested in the plasma.
Pharmacokinetic parameters. An atrioventricular model was used to calculate the pharmacokinetic parameters (Table II). Indole quinone was rapidly absorbed following lavage into Beagles and peaked in $<1 \mathrm{~h}$, while the drug concentration in the plasma decreased rapidly. After $8 \mathrm{~h}$, the prototype drugs could not be tested in the plasma. Elimination of the drugs in the body had no evident gender differences.

\section{Discussion}

As an endogenous component, indole quinone exists widely in human and animal bodies (2). The current results showed that the plasma concentration of indole quinone in the majority of the Beagles was relatively high but extremely low in certain Beagles, and could not be tested. The plasma of the Beagles was initially tested, followed by methodology validation and pharmacokinetic examination to select the Beagles whose blood concentration was lower than the minimum quantitative limit $1 / 10$. After $8 \mathrm{~h}$ of intravenous injection or intragastric administration, the prototype indole quinones could not be tested in the plasma of most of the Beagles, with the exception of some dogs, and this was considered an endogenous drug.

The clearance of Isatin in dogs was $6.64 \pm 1.54 \mathrm{l} / \mathrm{h} / \mathrm{kg}$, which is 6.64-fold that of the canine liver plasma flow (approximately $1.0 \mathrm{l} / \mathrm{h} / \mathrm{kg}$ ) (10). To calculate the average value of $\mathrm{AUC}_{0-\infty}$, the absolute bioavailability of $15 \mathrm{mg} / \mathrm{kg}$ Isatin given to lavage Beagles was $41.77 \%$, which was lower than the bioavailability $(57.75 \%)$ of rats, and could therefore be used as oral medicine (6). However, additional experiments are required to 
determine whether the drugs were likely to have renal excretion or liver metabolism.

\section{Acknowledgements}

This study was supported by the Natural Science Foundation of Shandong Province (no. ZR2013HM065) and the Science and Technology Bureau of Qingdao (no. 11-2-4-2-(4)-jch).

\section{References}

1. Hamaue N, Minami M, Terado M,Hirafuji M,Endo T, Machida M, Hiroshige T, Ogata A, Tashiro K, Saito H, et al: Comparative study of the effects of isatin, an endogenous MAO-inhibitor, and selegiline on bradykinesia and dopamine levels in a rat model of Parkinson's disease induced by the Japanese encephalitis virus. Neurotoxicology 25: 205-213, 2004.

2. Igosheva N, Lorz C, O'Conner E, Glover V and Mehmet H: Isatin, an endogenous monoamine oxidase inhibitor, triggers a dose- and time-dependent switch from apoptosis to necrosis in human neuroblastoma cells. Neurochem Int 47: 216-224, 2005.
3. Medvedev AE, Clow A, Sandler M and Glover V: Isatin: a link between natriuretic peptides and monoamines? Biochem Pharmacol 52: 385-391, 1996.

4. Yue W, Wang L, Liu Z, Zhang F and Zhou M: A preparation method of marine anti-cancer active drugs. Appl. 20041002387 1.1 (In Chinese).

5. Wang Y, Liu Z, Lei W, Zhong W, Yang Z and Xu M: The application of indole-2,3-diketone in the preparation of drugs on antivirus or immune-enhancer. Patent ZL10105691. Filed September 30, 2005; issued April 19, 2006.

6. Zhang Y and Yue W: The pharmacokinetic study of 2,3-indole quinones in rats. Chin Practic Med 6: 28-31, 2011.

7. Shah VP, Midha KK, Findlay JW, Hill HM, Hulse JD, McGilveray IJ, McKay G, Miller KJ, Patnaik RN, Powell ML, et al: Bioanalytical method validation - a revisit with a decade of progress. Pharm Res 17: 1551-1557, 2000.

8. Karnes HT and March C: Precision, accuracy, and data acceptance criteria in biopharmaceutical analysis. Pharm Res 10: 1420-1426, 1993.

9. Shen $X$ and Chen J: Certification of biological pharmaceutical analysis method. Chin Pharm J 24: 425-426, 1993.

10. Davies B and Morris T: Physiological parameters in laboratory animals and humans. Pharm Res 10: 1093-1095, 1993. 